\title{
The Impact of Positive Doctor Role Modelling
}

\section{ABSTRACT \\ Background}

Role modelling has been highlighted as an important teaching and learning strategy. The aim of this research study was to explore the influences and impact of positive doctor role modelling in $21^{\text {st }}$ century medical education.

\section{Methods}

This study was part of a larger study investigating the process of positive doctor role modelling in medical education. This study used focus group interviews with fifty two medical students, semi structured interviews with twenty five consultants and interviews after clinics with five consultants and five medical students. A qualitative methodology using the grounded theory approach of Strauss and Corbin was then used to explore the impact of modelling in medical education.

\section{Results}

Three main outcomes of role modelling were identified - the development of professional behaviours, the development of professional identity and the shaping of career aspirations.

\section{Conclusion}

This study illustrates the powerful, often subconscious impact of doctor role modelling in medical education. This research illustrates that role models are critically important in the professional development, character development and career development of the modellees. In this way, role modelling effectively enhances the transformation of the student to a doctor. 


\section{Introduction}

Doctor role modelling has been highlighted as an important teaching strategy in medical education (Irby 1986; Wright et al. 1998; Althouse et al. 1999; Cote and Leclere 2000; Paice et al.2002; Wright et al.2002; Kenny et al.2003; Weismann et al. 2006; Cruess et al. 2008; Passi et al. 2013). Role models have been described as 'individuals admired by their ways of being and acting as professionals' (Irby 1986). Role models in medical education are different from mentors as they influence and teach solely by example whereas mentors have a formal relationship with students (Ricer 1998). The relationship between the role model and modellee is quite unique in medical education as it is dependent on the choices made by the modellee (Passi and Johnson 2015).

This study was part of a larger study investigating the process of positive doctor role modelling (Passi and Johnson 2015). This research offered an explanation of what is happening in the doctor role modelling process. It was described as a "process that involves conscious and subconscious elements and consists of an Exposure Phase followed by an Evolution Phase. The Exposure phase involves demonstration of the professional attributes by the doctor role models. The Evolution phase begins with observation of the role model by the modellee, following which the modellee makes a judgement whether or not to trial the observed behaviours of the role model; when the decision to trial is reached, this then leads to a Model Trialling Cycle which involves five stages (assembly, emulation, experimentation, adaptation and assimilation)' ( Passi and Johnson 2015).

The aim of this part of the study was to investigate the impacts of positive doctor role modelling in medical education, and also to develop an understanding of the process by which role modelling brought about these impacts. Whilst recognising that role modelling can be positive or negative ( Cruess et al.2008), this study focused solely on positive role modelling with the aspiration that this could lead to strategies to improve positive role modelling in clinical practice - this in turn would ultimately ensure high professional standards of care.

\section{METHODS}

\section{Study design}

The methodology used has been described in a previous paper (Passi and Johnson 2015). In summary, a qualitative methodology using the grounded theory inquiry approach of Strauss 
and Corbin was used to generate a general explanation of the impact and influences of role modelling based on the views of participants (Strauss and Corbin 2008). This grounded theory approach uses iterative sampling, conceptual memoing and the simultaneous collection and analysis of data (Strauss and Corbin 2008). The research protocol, participant information sheet and consent forms were subject to external peer review and were subsequently granted institutional ethics committee approval.

\section{Participants and sampling}

The study was conducted at a UK medical school. The study involved three different methods to ensure a detailed exploration into the process of role modelling with triangulation of the data, participants and settings: focus groups with final year medical students; semi-structured interviews with consultants; and semi- structured interviews with medical students and consultants immediately after clinics. The third method was used to investigate the immediate impact of role modelling and thereby address the risk of recall bias.

An iterative purposive sampling technique was used to recruit volunteers and the recruitment was voluntary. Participants were students in the final year at a graduate entry medical school and consultants invited to cover the main range of clinical specialities. All participants were given participant information sheets and asked to sign informed consent papers. Participant recruitment was maintained until data saturation was achieved (Morse 1995).

Data collection and analysis The interviews lasted up to one hour. The focus group questions and semi structured interview questions explored aspects of the doctor role model and the role modelling process and are shown in Table 1 in the Appendix 1. All the data from the interviews were audiotaped and transcribed by the principal researcher. N-Vivo version nine, reference management software (QSR International) was used to facilitate the organisation of all the data systematically into themes. In line with the grounded theory approach' data analysis proceeded at the end of the interviews, prior to conducting the next interview (Strauss and Corbin 2008). A constant comparative approach was used to determine the breadth and characteristic of each category. Using the systematic approach of Strauss and Corbin (2008) open coding, axial coding and selective coding methods were employed to reveal the processes involved in role modelling. In axial coding, the four components are portrayed in a Coding Paradigm/ Logic Diagram (Strauss and Corbin 2008) which forms the basis of the theoretical model, developed in grounded theory and is illustrated in Figure 1 below. 


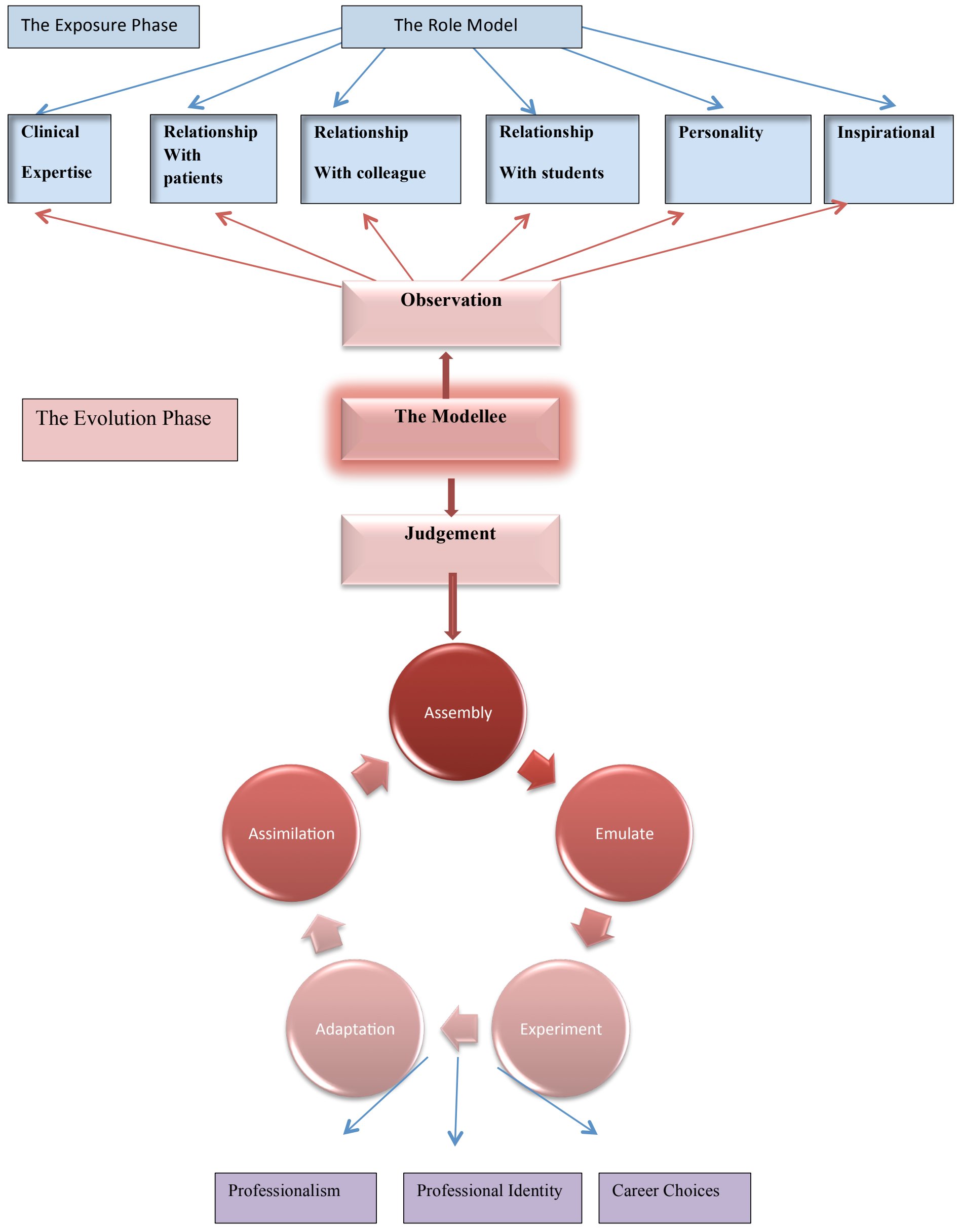




\section{RESULTS}

The study involved 25 consultants representing a total of 17 specialities (ten medical specialities, six surgical and general practice), with no more than three representatives from any one speciality. The study involved twelve medical student focus groups (fifty two students) and interviews with five consultants and five medical students after outpatient clinics. The components of the Strauss and Corbin Grounded Theory Methodology (central phenomenon, causal conditions, strategies and consequences) are described in the previous paper (Strauss and Corbin 2008). Three main outcomes of role modelling were identified the development of professional behaviours, the development of professional identity and the shaping of career aspirations. The outcomes are described in detail below.

\section{The Influence of Role Modelling in Developing Professionalism}

This section describes some key reflections from the participants on the development of professionalism. The medical students highlight the importance of having the input of many consultants to develop your professionalism,' and to help them develop their 'professional role.' The students succinctly emphasise that modelling is important to learn how to 'show your professionalism.' These three themes and associated transcripts are illustrated below. In the transcripts below, $\mathrm{C} 1, \mathrm{C} 1, \mathrm{C} 2$ denotes the consultant and G1M1 denotes focus group one, male student etc.

\footnotetext{
It is important that we have input from so many different consultants ... a lot of people will help you develop your professionalism (G11M2)

Role modelling is really important ... we develop our professional role with patients, colleagues.... We learn how to behave. (G8F2)

It is how you learn about showing your professionalism.... it is something that you have got but then you need to show it. (G2F3)

You can't be shown how to care for people but you can be taught to show how you care for people. (G2F1)
}

The Consultants reflecting back on their own training similarly illustrate how role models influenced their 'professional development.' It was stated that 'different aspects of professionalism are modelled at different stages of training.' The importance of role modelling in developing professionalism was noted as 'you cannot give a lecture on 
professionalism and hope they become professional.' The importance of role modelling as a teaching strategy was noted as 'issues such as integrity are difficult to teach.'

In training - many role models influenced my professional development ....part of professionalism is having the humility to say that I know that I should be doing this but I am not up to that procedure now and asking colleagues for help. (C22)

There are different aspects of professionalism modelled at different stages of training ... in medical students it is general aspects such as be nice .... Be professional to patients / colleagues ... (C10).

Role modelling is important in professionalism...as issues such as integrity are difficult to teach ... you cannot push/ you just have to let it come out. ..You cannot give a lecture on professionalism and hope they become professional. (C9)

In clinical years ...... Role models show you culture, respect for patients, clinical signs etc. (C20)

\section{The Influence of Role Modelling in the Development of Professional Identity}

This section describes the influence of role modelling in the development of professional identity. Both the Consultants and students describe the nurturing impact of role modelling as 'moulding.' A student states the process as 'moulding of our professional identity.' A consultant describes the process as being 'groomed from day one as we know what the public expect.' An important point made by a Consultant was that 'being a good role model is extremely vital for bringing up good models for the future.'

There was a consultant who really made me into consultant material ... it was his personality .... He moulded me into consultant material. (C11)

In medicine you are being groomed from day one ... we know what the public expect .... So there is a degree of moulding. (C26)

Some of us had previous careers ... but we try different things and see what works. This is moulding of our professional identity. (G7M2)

See what want to see and mould themselves to that. (G7M4)

People are moulded by the environments in which they are in. Different specialities have different environments and attract similar people. (G7M2)

Doctors are human beings ... so their emotions can influence their day to day activities .... Being a good role model is extremely vital for bringing up good role models for the future .... No doubt about it .... I have worked with wonderful professors ... the way you communicate, discuss things with the family, explain things to the patient .... There is something about certain born doctors ... I could not do anything else (Consultant 12) 
The evidence highlights that the participants developed an 'idea of what type of doctor' they would want to be through role modelling and this usually occurs at the end of training. The students emphasise the value of emulating the role model's unique approach and 'styles.' One student stated that 'good models from various doctors helped me be a unique doctor of my own.'

You know what type of doctor that you do not want to be.... You know how to do it .... Further in your training - you can be more judgmental about other people's styles and think that that is definitely what I do not want to do. (G5F1)

The way that certain consultants speak to a patient .... Make them feel comfortable, at ease ..... A fairly relaxed consultation style ...... and I feel that I have developed that as well. I tend to have developed a friendly approach ... at the time when I looked at the consultant .... I thought that 'that is want I want to be like when I am a doctor.' (G11M1)

There were people I thought that I would like to be like that or be perceived like that (Consultant 4)

Role models are absolutely important.. at the end of the day we want to be good doctors ......good models from various doctors helped me to be a unique doctor of my own. (Consultant 1)

\section{The Influence of Role Models in Influencing Career Choices}

The Consultants reflecting on their own career describe how their role models influenced their career choice and sometimes it can be several role models or just one role model. This 'vital' influence by the role models was emphasised. The Consultants were influenced by role models who 'inspired' them during their training and who they 'admired.'

From the clinical perspective ...... There are several people in the Accident and Emergency world ..... who have inspired me or led me down the path that I have ended up ...(C14).

I think it is vital .... As it is the way we are enthused in medicine ... I was very influenced in surgery by the people I worked with

Role models are vital, vital .... You do things that you find has been very good as a student ..... I became a urologist because I was taught extremely well within the urology departments .... Great teachers .... For me no other reason .... I think that role models are very important. (C13)

I was influenced by one person ... I was doing cardiology at the time ... he opened my eyes to the possibilities and made it sound exciting and so yes, definitely influenced my career. (C3) 
A gastroenterologist I worked with inspired me to be a gastroenterologist ... I know that you cannot just choose your speciality because of the person you like .... but it does make a difference to your career path. (C10)

Of course... yes ....the reason why I have become a neurologist ... is because of my role model.... Because of just one person and I have yet to see such a great person..... I do not feel that I would be able to do another profession. (C12).

The medical students similarly highlight the influence of role models on choosing career choice. This influence is twofold- first, the students observe the clinical teacher 'enjoying' their work and having 'high job satisfaction and love their job.'

But it makes the subject look attractive because if they are doing it and enjoying it. (G2M1)

Even though I know how hard surgery is ..... I am really interested in it ..... because all the surgeons have such high job satisfaction and love their job. (G9M1)

It is hard as a student to know what you want to do as a career.... If you see a doctor you admire doing a job that you think you might enjoy .....that naturally makes a huge difference on our future prospects. (C1F2)

Second, the students' own personal 'positive experiences' within that speciality block influence their career choice. The learning 'environment' was also an important influence on career choice. The students described how they often changed their original career choice after gaining experience in a different speciality.

Our positive experiences .... Have a positive bias toward it. (G9M1).

Obs and gynae block .... Teachers were keen to teach and friendly .....made me think that now I know what to do. (G6F2)

I also liked GP ... I initially thought that I would never like it but I did ....everyone was so lovely ... with me, each other and the patients ... it was a lovely environment to work in. (G6M1)

I was initially quite interested in casualty ... but in general practice..... I felt more comfortable in that environment and I am more drawn to it. (G6F1)

The students also highlight the element of discovery in that their role models inspired them to consider specialities that they may otherwise not have chosen. The descriptions are very explicit as students describe how the role models have influenced their career choice. As a student confidently stated ' $I$ am now definitely and seriously considering surgery as a career... before this block, I had completely written surgery off.' 
The orthopaedic consultant was inspiring .... Although I did not see myself as an orthopaedic surgeon... I could see myself doing orthopaedics based on what he brought to the job. (C1M1)

Our Orthopaedic Consultant was authoritative but made it worthwhile ... we would be scrubbed up in theatre and we would have huge experience in surgery .... Hammering the bones and suturing ...... he really engaged us as a teacher .....I am now definitely and seriously considering surgery as a career ...... before this block, I had completely written surgery off. (C18M1)

Cardiology and anaesthetics ...prior to that I thought that I would just take it as it comes .... but now after cardiology I thought 'wow, I like that'( G4F3)

Before I came to medical school ... I thought paediatrics would be my worst nightmare .....but after doing a block it has changed my way of thinking. (G6F3)

The medical students also described that they may choose the speciality choice because they really like the role model (the person) rather than the speciality. As described by a student in that 'it can be quite dangerous because often you like a consultant and you think that you would like to do that speciality but really it is because you like the consultant.' The transcripts below highlight the strong influence of the individual role models on careers.

It can be quite dangerous because often you like a consultant and you think that you would like to do that speciality but really it is because you like the consultant. (G2F2)

It is massive ... I am worried that my career choice of endocrinology may be because I had such a good consultant. (G9M2)

We do talk a lot about what we think of different consultants ...some people everyone likes them and those people are held in high esteem ...it does influence what speciality we choose. (G4F2)

I absolutely loved my GP (G6F2)

It is silly in a way ...not rational...but probably does influence our career choice. (G4M1)

We have had good consultants .... It does affect our career choice. (C1F1)

Finally, an important theme was that although the consultants gave detailed descriptions of their own role models, when interviewed they did not perceive themselves as a role model. Table 2 in the Appendix illustrates the explicit and detailed descriptions of the characteristics and influences of the role models chosen by ten consultants of different specialities during 
their own careers. In contrast, they all state that they do not consciously try to be a role model for their students as many state that they ' do not consider myself a role model,' and 'many had not thought about' being a role model in clinical practice.

\section{DISCUSSION}

This study was part of a larger study investigating the process of positive doctor role modelling (Passi and Johnson 2015). The previous study revealed that the process of role modelling involves an exposure phase followed by an evolution phase as shown in Figure 1 in the Appendix. This study illustrated three important influences of role modelling, namely the development of professionalism, the development of professional identity and the shaping of career choices.

The development of medical professionalism in medical education serves important societal purpose (Cruess et al. 2000). Medical schools throughout the world have acknowledged the importance of incorporating professionalism into the undergraduate medical curriculum and there are many descriptions of various curricula that medical schools have designed to integrate professionalism (Stephenson et al. 2001; Steinert et al. 2005; Stephenson et al. 2006; Goldie 2008; Parker et al 2008). A recent systematic review highlighted five main approaches to developing professionalism which included curriculum design, teaching and learning methods, assessment methods and role modelling (Passi et al. 2000). This study expands our knowledge regarding the influence of role modelling in developing medical professionalism.

This study illustrates how the role models influence the development of professionalism. First, positive doctor role models exert this subtle influence by demonstrating to students 'how to behave' professionally with patients. Second, the evidence describes how positive role models help the students develop their own 'professional role' in practice. Third, the consultants emphasised that role modelling is imperative as many professional attributes such as 'integrity' are difficult to teach. Through the model trialling cycle described in the original paper (Passi and Johnson 2015), the modellees can emulate these professional behaviours into their own practice. A recent systematic review synthesised the evidence on teaching professionalism and stated that there was no unifying theory or practical model to teach professionalism and concluded that role modelling and personal reflections were key elements (Birden et al 2013). This research study paves the way for explaining in detail how role modelling influences the development of medical professionalism in medical education. 
This research study also illustrated how role modelling influences the professional identity of the students. Professional identity formation has been described as 'ways of being and relating in professional contexts' (Goldie 2012). The development of professional identity is imperative for medical students in their journey from being a medical student to becoming a practising clinician. During this journey, students develop an understanding of their new role and an understanding about the boundaries of their profession. There are no current guidelines on how best to develop professional identity formation (Adams et al. 2006). However, there was strong evidence in this study of how role modelling enhanced the process of identity formation and this was explicitly described in this study as 'moulding' or 'grooming,' throughout the curriculum.

Professional identity formation is important as it helps students to gain a realistic view of the profession. The ways in which medical students develop their professional identity has important implications for their own performance and developing effective relationships with colleagues (Monrouxe 2010). To achieve this, students need to primarily interact with members of the medical profession (Monrouxe 2010; Goldie 2012) and this research study findings illustrate that this can effectively be achieved by positive doctor role modelling. An important nuance noted in this study was that role models help the student develop their own 'idea of what type of doctor they would like to be.' Through the model trialling cycle described in the evolution phase of the role modelling process (Passi and Johnson 2015), the modellees can inculcate these professional characteristics.

The challenge for medical educators is that the development of professionalism and professional identity is often subconscious and depends on the student making the correct judgement about whether or not it is a 'good' model to emulate. Figure 1 in the Appendix illustrates that the judgment phase in the role modelling process takes place prior to the model trialling cycle (Passi and Johnson 2015). The evidence available on negative modelling highlights that it tends to occur in the informal aspects of the curriculum, often creating a conflict for students with regard to what has been taught in the formal curriculum and what is observed in the informal curriculum (Mutha and Takayama 1997; White et al. 2009). Therefore, medical educators need to support students to develop their ability to discriminate between positive and negative behaviours to ensure they will emulate positive behaviours. 
The third important influence of role modelling was on the shaping of career choices. Career choices in medicine are complex, multidimensional and individualised processes (Basco and Reigart 2001). A systematic review on role modelling highlighted the influence of role models on career choices (Passi et al. 2013).The existing literature describes that in undergraduate education, many medical students had identified their career influencing role models by the time of graduation (Watts et al. 1998; Basco and Reigart 2001). In postgraduate education, the career influencing role models were identified as those who encouraged active participation, offered good support and taught advanced skills (Henderson et al. 1996; Berman et al. 2008; Lombarts et al. 2010; Ravindra and Fitzgerald 2011). The findings in this study enhance our understanding of how role models shape career choice, describing how role models do not always actively try to recruit students to join their specialties but by demonstrating enthusiasm, job satisfaction and passion for their work had an important influence on student choice. The students explicitly described the element of discovery in that their chosen role models inspired them to consider specialities that they may otherwise not have chosen. Many students stated that they may choose the speciality because they were inspired by the role model rather than the speciality and this shows the powerful impact of role models in the exposure phase (Passi and Johnson 2015) of the process of role modelling.

With regard to the impact on career choices, clinical teachers must be aware of their impact on the recruitment and retention of learners into all specialities (Curran and Rourke 2004). However, an important emergent theme was that although the consultants gave detailed descriptions of their own role models, when asked, they did not perceive themselves as a role model. This finding highlights the importance for doctors to develop a conscious awareness of being a role model in all clinical environments and their potential influence on the career choices of students.

\section{Conclusion}

This study illustrates the powerful, often subconscious impact of doctor role modelling in medical education. This research illustrates that role models are critically important in the professional development; character development and career development of the modellees. In this way, role modelling effectively enhances the transformation of the student to a doctor.

The implications for medical educators are important: First, there are currently no consensus guidelines on how best to develop medical professionalism and positive role modelling 
provides a powerful teaching strategy for this. Second, the development of professional identity is a complex, often subconscious process that effectively takes place through positive role modelling throughout the curriculum. Third, this study provides strong justification for the impact role models have on the career choices and hence all clinical teachers need to embrace their potential role model status. Therefore, medical leaders worldwide must embrace role modelling as important teaching strategy and develop strategies to ensure a culture of positive modelling in all learning environments. This in turn will lead to an inspirational, dedicated and enthusiastic medical workforce.

\section{Author Contributions}

Dr Vimmi Passi was the lead researcher who made the main contribution to the study design, data collection, data analysis, data interpretation and writing of this article.

Professor Neil Johnson was the lead supervisor who advised on the study design, data interpretation and writing of this article.

Acknowledgement: Professor Ed Peile for his support and advice throughout the research study.

Declaration: No conflicts of interest.

Funding: No funding obtained for this study

Ethical Approval: NHS REC ethical approval for the study was obtained. 


\section{REFERENCES}

1. Adams $\mathrm{K}$ et al. (2006) Investigating the factors influencing professional identity in the first year of health and social care students. Learning in Health and Social Care, Volume 5 (2): 55-68.

2. Althouse, L. A., Stritter, F. T. \& Steiner, B. D. (1999) Attitudes and Approaches of Influential Role Models in Clinical Education. Advances in Health Sciences Education, 4 (2): 111-122.

3. Basco, W. T., Jr. \& Reigart, J. R. (2001) When do medical students identify careerinfluencing physician role models? Academic Medicine, 76 (4): 380-382.

4. Berman, L., Rosenthal, M. S., Curry, L. A., Evans, L. V. \& Gusberg, R. J. (2008) Attracting Surgical Clerks to Surgical Careers: Role Models, Mentoring, and Engagement in the Operating Room. Journal of the American College of Surgeons, 207 (6): 793-800.e792.

5. Birden H, Glass N, Wilson I, Harrison M, Usherwood T, Nass D. (2013) Teaching professionalism in medical education. A Best Evidence Medical Education (BEME) Systematic Review. Medical Teacher, 35(7), e1252-e1266.

6. Cote L and Leclere H. (2000) How clinical teachers perceive the doctor-patient relationship and themselves as role models. Academic Medicine, 75(11): 1117-1124.

7. Cruess RL, Cruess SR, Johnson SE. Professionalism and medicine's social contract (2000). J Bone Joint Surg Am, 82:1189-1194.

8. Cruess, S. R., Cruess, R. L. \& Steinert, Y. (2008) Role modelling - making the most of a powerful teaching strategy. British Medical Journal, 336 (7646): 718-721.

9. Curran V, Rourke J. (2004) The role of medical education in the recruitment and retention of rural physicians. Medical Teacher, 26:265-72.

10. Goldie J. Integrating professionalism teaching into undergraduate medical education in the UK setting. (2008) Medical Teacher, 30:513-527.

11. Goldie, J (2012). The formation of professional identity in medical students: considerations for educators. Medical Teacher, 34(9), p641-648.

12. Henderson, M. C., Hunt, D. K. \& Williams, J. W. (1996) General internists influence students to choose primary care careers: The power of role modelling. American Journal of Medicine, 101 (6): 648-653.

13. Irby DM ( 1986) Clinical teaching and the clinical teacher. J Med Educ, 61(2): 35-45.

14. Kenny, N. P., Mann, K. V. \& MacLeod, H. (2003) Role modelling in physicians' professional formation: reconsidering an essential but untapped educational strategy. Academic Medicine, 78 (12): 1203-1210.

15. Lombarts, K. M., Heineman, M. J. \& Arah, O. A. (2010) Good clinical teachers likely to be specialist role models: results from a multicenter cross-sectional survey. PLoS One, 5 (12): e15202.

16. Monrouxe L.V (2010) Identity, identification and medical education: why should we care? Medical Education; 44: 40-49.

17. Morse JM (1995) The significance of saturation. Qual Health Res, 5: 147-149.

18. Mutha S and Takayama J. (1997) Insights into medical students' career choices based on third and fourth year students' focus group discussions. Academic Medicine, 72: 635-640.

19. Paice E, Heard S, Moss F. (2002) How important are role models in making good doctors? British Medical Journal, 325:707-710. 
20. Passi, V., Doug, M., Peile, E., Thistlethwaite, J. \& Johnson, N. (2010) Developing medical professionalism in future doctors: a systematic review. International Journal of Medical Education, 1: 19-29.

21. Passi V, Johnson S, Peile E, Wright S, Hafferty F and Johnson N. (2013) Doctor Role Modelling in Medical Education. BEME Guide No. 27. Medical Teacher, 35: e1422e1436.

22. Passi V and Johnson N. (2015) The Hidden Process of Positive Doctor Role Modelling. Accepted in Medical Teacher (20th August 2015).

23. Parker M, Luke H, Zhang J, Wilkinson D, Peterson R, Ozolins I. (2008) The pyramid of professionalism: seven years of experience with an integrated program of teaching, developing and assessing professionalism among medical students. Academic Medicine, 83:733-741.

24. QSR International NVivo 9. http://www.qsrinternational.com/products.nvivo.aspx.

25. Ravindra, P. \& Fitzgerald, J. E. F. (2011) Defining Surgical Role Models and Their Influence on Career Choice. World Journal of Surgery, 35 (4): 704-709.

26. Ricer RE. (1998) Defining preceptor, mentor and role model. Fam Med 30(5): 328.

27. Steinert, Y., Cruess, S., Cruess, R. \& Snell, L. (2005) Faculty development for teaching and evaluating professionalism: from programme design to curriculum change. Medical Education, 39 (2): 127-136.

28. Stephenson A, Higgs R, Sugarman J. (2001) Teaching professional development in medical schools. Lancet, 35: 867-870.

29. Stephenson AE, Adshead LE, Higgs RH. (2006) The teaching of professional attitudes within UK medical schools: Reported difficulties and good practice. Medical Education, 11:1072-1080.

30. Strauss A and Corbin J (2008). Basics of Qualitative Research, $3^{\text {rd }}$ Edition. Thousand Oaks. Sage.

31. Watts, R. W., Marley, J. \& Worley, P. (1998) Undergraduate education in anaesthesia: The influence of role models on skills learnt and career choice. Anaesthesia and Intensive Care, 26 (2): 201-203.

32. Wear, D., Aultman, J. M., Zarconi, J. \& Varley, J. D. (2009) Derogatory and cynical humour directed towards patients: views of residents and attending doctors. Medical Education, 43 (1): 34-41.

33. Weissmann PF, Branch WT, Gracey CF, Haidet P, and Frankel RM. (2006) Role modelling humanistic behaviour: learning bedside manner from the experts. Academic Medicine; 81: 661-667.

34. Wright, S. M., Kern, D. E., Kolodner, K., Howard, D. M. \& Brancati, F. L. (1998) Attributes of excellent attending-physician role models. New England Journal of Medicine, 339 (27): 1986-1993.

35. Wright, S. M. \& Carrese, J. A. (2002) Excellence in role modelling: insight and perspectives from the pros. CMAJ, 167 (6): 638-643.

36. White, C. B., Kumagai, A. K., Ross, P. T. \& Fantone, J. C. (2009) A qualitative exploration of how the conflict between the formal and informal curriculum influences student values and behaviors. Academic Medicine, 84 (5): 597-603. 


\section{Appendix}

\section{Table 1: The Interview Questions}

\begin{tabular}{|c|c|}
\hline Student Focus Group & $\begin{array}{l}\text { - Have you had many doctor role models during your training? } \\
\text { - How many role models have you had in your training? } \\
\text { - What were the characteristics of these doctor role models? } \\
\text { - What are the influences of doctor role models? } \\
\text { - } \quad \text { At where does role modelling take place? } \\
\text { - How does the actual process of role modelling occur? } \\
\text { - How important is role modelling in developing professionalism? } \\
\text { - How would you define the term doctor role model? }\end{array}$ \\
\hline $\begin{array}{l}\text { Semi Structured Interview } \\
\text { Consultant Interviews }\end{array}$ & $\begin{array}{l}\text { Looking back to your own undergraduate and postgraduate training : - } \\
\text { - Have you had many doctor role models during your training? } \\
\text { - How many role models have you had in your training? } \\
\text { - What are the characteristics of these doctor role models? } \\
\text { - What are the influences of doctor role models? } \\
\text { - } \quad \text { Ht what stages of training does role modelling occur? } \\
\text { - How does the actual process of role modelling occur? } \\
\text { - How important is role modelling in developing professionalism? } \\
\text { - How would you define the term doctor role model? } \\
\text { - } \text { - Do you consider yourself a doctor role model? } \\
\text { - Ho you think about and use 'role modelling' during clinical practice? } \\
\text { - How important is role modelling in your current educational role? }\end{array}$ \\
\hline Interview after Clinics & $\begin{array}{l}\text { Interview questions for medical students immediately after clinic : - } \\
\text { - What positive role modelling did you observe in clinic? } \\
\text { - How did the consultants model this? } \\
\text { - Which aspects will you model in the future? } \\
\text { - Any other thoughts on the process of doctor role modelling? } \\
\text { Interview questions for consultants immediately after clinic : } \\
\text { - What positive role modelling did you demonstrate in clinic? } \\
\text { - How did you model this? Where you thinking about the modelling } \\
\text { - } \text { process? } \\
\text { - What aspects would you like the student to model in the future? } \\
\text { - Any other thoughts on the process of doctor role modelling? }\end{array}$ \\
\hline
\end{tabular}


Table 2: The Consultant's Role Model versus the Consultant as a Role Model

\begin{tabular}{|c|c|}
\hline Consultant's Role Model & The Consultant as a Role Model \\
\hline $\begin{array}{l}\text { Consultant Gastroenterologist ( C25) } \\
\text { - There were many people I admired } \\
\text { throughout my training. } \\
\text { As a gastroenterologist ... I worked with a } \\
\text { consultant who inspired me to be a } \\
\text { gastroenterologist ...I know you cannot } \\
\text { choose your speciality because of the person } \\
\text { you like .... but it does make a difference to } \\
\text { your career path. } \\
\text { It can be often many people that we take } \\
\text { things from. }\end{array}$ & $\begin{array}{l}\text { Consultant Gastroenterologist ( C25) } \\
\text { - I do not consider myself a role model in that } \\
\text { sense (shuffles and laughs) but we are aware } \\
\text { that the students are observing our } \\
\text { behaviours. }\end{array}$ \\
\hline $\begin{array}{l}\text { Consultant Paediatrician ( C2) } \\
\text { - I had many role models in training - people } \\
\text { whose skills I value .. it was very important. } \\
\text { - I think professionalism, diagnostic ability, } \\
\text { logical approach to the diagnostic process } \\
\text { and wiseness. }\end{array}$ & $\begin{array}{l}\text { Consultant Paediatrician ( C2) } \\
\text { - I guess I am really ..... although I do not } \\
\text { actually think of myself like that really ..... } \\
\text { but I guess I am really. }\end{array}$ \\
\hline $\begin{array}{l}\text { Consultant Surgeon ( C8) } \\
\text { - I worked in a missionary hospital.. the man } \\
\text { who ran the hospital was a great role model } \\
\ldots . \text { He was impossible to be like, he was } \\
\text { wonderful, capable. }\end{array}$ & $\begin{array}{l}\text { Consultant Surgeon ( C8) } \\
\text { - I don't like it ... but I am sure you are right } \\
\ldots . \text { The students notice ... they notice all } \\
\text { those bad things about me which I wish they } \\
\text { didn't. }\end{array}$ \\
\hline $\begin{array}{l}\text { Consultant Paediatrician ( C9) } \\
\text { - There were two consultants .... They were } \\
\text { both incredible ... they ran the paediatric } \\
\text { unit. }\end{array}$ & $\begin{array}{l}\text { Consultant Paediatrician ( C9) } \\
\text { - } \begin{array}{l}\text { Hesitates .... sighs.... Well I hope that there } \\
\text { are traits that people can resonate with me. }\end{array}\end{array}$ \\
\hline $\begin{array}{l}\text { Consultant Urologist ( C13) } \\
\text { - Role models are vital, vital. } \\
\text { - I think professional role models are very } \\
\text { important } \\
\text { - I have never met such a nice professor of } \\
\text { Urology }\end{array}$ & $\begin{array}{l}\text { Consultant Urologist ( C13) } \\
\begin{array}{l}\text { - } \\
\text { - } \\
\text { - } \\
\text { I cannoty my say ... } \\
\end{array}\end{array}$ \\
\hline $\begin{array}{l}\text { Consultant Cardiologist ( C15) } \\
\text { - } \quad \text { Role modelling is important } \\
\text { - I had a consultant who was brilliant but at the } \\
\text { same time we had great fun. }\end{array}$ & $\begin{array}{l}\text { Consultant Cardiologist ( C15) } \\
\text { - I do not think of myself as a role model but } \\
\text { more as a helpful, friendly advisor. } \\
\text { - I guess ... I suppose I must be .... But it is } \\
\text { not how I look at myself. }\end{array}$ \\
\hline
\end{tabular}




\begin{tabular}{|c|c|}
\hline Consultant's Role Model & Consultant as a Role Model \\
\hline $\begin{array}{l}\text { Consultant Urologist ( C21) } \\
\text { - The most positive role model was my father } \\
\text { who was a GP.... all the patients loved him. }\end{array}$ & $\begin{array}{l}\text { Consultant Urologist ( C21) } \\
\text { - Pause ... sighs ...no because I have not } \\
\text { thought about it. } \\
\text { - I am not trying to be a role model ....I am } \\
\text { interested in the patients first .. the students } \\
\text { can take what they want. }\end{array}$ \\
\hline $\begin{array}{l}\text { Consultant Otolaryngologist ( C22) } \\
\text { - Professor of max fax was a good role model } \\
\text {.... He had presence of character. }\end{array}$ & $\begin{array}{l}\text { Consultant Otolaryngologist ( C22) } \\
\text { - Maybe... } \\
\text { - The students do not spend enough time with } \\
\text { me to pick up the important little bits. } \\
\text { - I may be fairly easy going ... but I keep a } \\
\text { close eye on what is going on ....and make } \\
\text { sure everything is fine. The students may not } \\
\text { see this part of me. }\end{array}$ \\
\hline $\begin{array}{l}\text { Consultant Cardiologist ( C3) } \\
\text { - If I think back to people I remember most } \\
\ldots . \text { some of them had a presence ... which is } \\
\text { something you just do.... }\end{array}$ & $\begin{array}{l}\text { Consultant Cardiologist ( C3) } \\
\text { - I would not say that I am out to inspire } \\
\text { people to do cardiology } \\
\text { But the more interested the people are } \ldots . . \\
\text { the more likely you are to promote that. }\end{array}$ \\
\hline $\begin{array}{l}\text { Consultant Nephrologist ( C17) } \\
\text { - Oh yes .. there were plenty who inspired me. } \\
\text { - There were individuals who demonstrated } \\
\text { clear motivation to patient care and care to } \\
\text { colleagues. It was quite striking. }\end{array}$ & $\begin{array}{l}\text { Consultant Nephrologist ( C17) } \\
\text { - Being a role model is a passive state ... you } \\
\text { are there and they take the bits they like. } \\
\text { You can only throw out what you have got } \\
\text { and they will pick up the stuff they like that } \\
\text { suits them. }\end{array}$ \\
\hline
\end{tabular}

